\title{
Reflexões sobre envelhecimento e trabalho
}

\section{Reflexions about aging and work}

Rosangela Ferreira deSouza ${ }^{1}$

Hernani Aparecido M atias ${ }^{1}$

Ana Cristina Passarella Brêtas ${ }^{1}$

Abstract This qualitative research has the aim to know the meaning of the aging process in the work market referring to theaged people. Six aged persons have participated in this research. The data were collected through an interview and were analyzed using the technique of thematically analyze. Three analytical categories emerged: the meaning of aging/to beaged; the meaning of work; the meaning of aging in the work. Concluding, this paper reinforces the theory that the capitalist societies attach excessive value to the work in the human being life. When it isn't into the life because of the retirement or the unemployment it compromises the quality of aging/to be aged of the person, mainly if skills and (individual, social and economical) conditions will lack participation and priority to others activities and values in her/his life.

Key words Aging, Labor, Q ualitative research
Resumo Esta pesquisa qualitativa teve por obje tivo conhecer o significado do processo de enveIhecimento no mercado de trabalho para idosos. Participaram do estudo seis idosos. Os dados foram coletados por meio de entrevista eanalisados utilizando a técnica da análise temática. Emergiram três categorias analíticas: o significado do envelhecimento/velhice; o significado do trabaIho; 0 significado de envel hecimento no trabalho. À guisa de conclusão, o estudo reforça a tese de que as sociedades capitalistas supervalorizam 0 trabalho na vida dos seres humanose, quando ele deixa de ser vivenciado - pela aposentadoria ou pelo desemprego -, compromete a qualidade do envelhecimento/velhice do indivíduo, principalmentese Ihe faltarem habilidades e condições (individuais, sociais e econômicas) para incorporar epriorizar outras atividadesevaloresem sua vida. Palavras-chave Envelhecimento, Trabalho, Pesquisa qualitativa

\footnotetext{
${ }^{1}$ Núcleo deEstudose Pesquisas sobre Saúde, Políticas Públicas e Sociais, Departamento de Enfermagem da UniversidadeFederal deSão Paulo. Rua Napoleão de Barros 754, Vila Clementino 04024-002 São Paulo SP. ro.brisa@uol.com.br
} 
Introdução

Se 0 aposentado fica desesperado com a falta de sentido de sua vida presente, é porque o sentido de sua existência sempre lhe foi roubado ${ }^{1}$ (p. 668).

Entendemos o envelhecimento como fenômeno natural e processual, que vai do útero ao túmulo. Para nós, o processo de envelhecimento é compreendido como processo de vida, ou seja, envel hecemos porque vivemos emuitas vezes sem nos darmos conta disso. 0 processo de envelhecimento comporta, portanto, a fase da velhice, mas não se esgota nela. A qualidade de vida e, consequentemente, a qualidade do envelhecimento se relacionam com a visão de mundo do indivíduo e da sociedade em que ele está inserido, assim como com o "estilo de vida" conferido a cada ser'. É nesse contexto que buscamos compreender o significado (atitudes, crenças e valores) do processo de envelhecimento no mercado de trabalho para idosos(as) que frequentam um equipamento social destinado à sua convivência.

Por sua vez, o trabalho é um processo de que participam o homem e a natureza, processo em que o ser humano, com sua própria ação, impulsiona, regula e controla seu intercâmbio material com a natureza. [...]. Põe em movimento as forças naturais de seu corpo - braços e pernas, cabeça e mãos - , a fim de apropriar-se dos recursos da natureza, imprimindo-Ihes forma útil à vida huma$n a^{3}$. N essa perspectiva, a utilização da força de trabalho é o próprio trabalho, e como tal é uma atividade exclusi vamente humana.

0 trabalho é o fundamento da vida humana e, em determinado aspecto, criou o próprio homem. Depois da palavra articulada, o trabalho foi o marco decisivo da transformação evolutiva do cérebro do macaco em cérebro humano. Assim, depreendemos que o ser humano se distingue dos outros animais porque, além de utilizar o esforço do corpo no processo de trabalho, utiliza a mente, e é capaz de projetar a transformação que fará ao material sobre o qual opera, antes de iniciá-la. Ele imprime a sua vontade ao processo de trabalho $0^{3,4}$.

Para pensar na articulação entre envelhecimento etrabalho, tomamos como ponto de partida a reflexão sobre a sociedade capitalista, tendo em vista que éa hegemônica no contexto histórico em que vivemos - cuja essência, segundo M arx, é a exploração pelo trabalho.
Nesse sentido, a característica principal da sociedade é a transformação do trabalho em mercadoria, sujeita como qualquer outra à lei da oferta e da procura. Para Marx, o modo como os indivíduos produzem sua vida material tem uma relação direta com o desenvolvimento político, social e cultural. Assim, o modo de produção capitalista é um sistema produtor de mercadorias em que o ser humano é alienado de sua própria essência, o trabalho. A alienação à qual 0 indivíduo é submetido sob essas condições se estende para o resultado do seu próprio trabaIho, pois o produto do trabalho não Ihe pertence, o que o torna um apêndice da máquina que Ihe dita o ritmo do trabalho ${ }^{3}$.

Para organizar o processo de trabalho, os capital istas sempre estabeleceram formas de gestão do trabalho, nas quais, por meio da racionalização da produção para obter maiores lucros, disciplinam os corpos individuais e coletivos dos trabalhadores. $\mathrm{Na}$ atualidade, utilizam com predominância modelos fundamentados em pensamento conservador e em políticas de corte neoliberal, defendendo, entre outras coisas, a redução de postos de trabalho, a desregulamentação e a flexibilização dos direitos do trabalho. Tal atitude traz consequências perversas no interior do mercado detrabalho em particular eda sociedade de uma forma geral - fragmenta, desqualifica e subproletariza ainda mais a classe que vive do trabalho ${ }^{5}$.

Nesse contexto, trazemos à reflexão a questão relacional estabelecida entre os conceitos envelhecimento e trabalho. Concordamos com Beauvoir ${ }^{1}$ quando diz que mais escandaloso do que o tratamento destinado à velhice éo empregado à mai oria dos seres humanos na juventude e na maturidade, uma vez que a sociedade capitalista só se preocupa com os indivíduos na medida em que produzem força de trabalho. Por sua vez, na medida em que trabalhamos, enveIhecemos, nem sempre tendo autonomia para escolher a forma para viver.

\section{Objetivo}

Conhecer o significado (atitudes, crenças evalores) do processo de envel hecimento no mercado de trabalho para gerontes que frequentam um equipamento social destinado à convivência de idosos é o objetivo deste trabalho. 


\section{Percurso metodológico}

Tipo de estudo

Este trabalho é uma pesquisa de natureza qualitativa, construído na perspectiva dialógica e relacional.

Local do estudo

0 estudo foi realizado em um equipamento social destinado à convivência de idosos. 0 lugar é mantido por uma entidade social sob a supervisão de técnicos da Secretaria M unicipal deAssistência e Desenvolvimento Social da Prefeitura Municipal de São Paulo e se destina aos idosos que vivem na área adstrita ao serviço.

\section{Sujeitos do estudo}

As entrevistas foram realizadas com seis pessoas, sendo quatro homens e duas mulheres, escolhidos por terem 60 anos ou mais de idade; frequentarem o espaço de convivência há pelo menos um ano; pertencerem a diferentes classes sociais; terem estado e/ou estarem inseridos no mercado de trabalho.

A definição dos sujeitos foi feita com o auxílio da equipe técnica do equipamento social, que agendou uma reunião com os idosos para que os pesquisadores pudessem apresentar o projeto de pesquisa em pauta. $\mathrm{Na}$ ocasião, os idosos foram convidados a participar do estudo - dos 15 presentes, seis se colocaram à disposição para entrevista.

\section{Coleta de dados}

Os dados foram coletados no segundo semestre de 2004 por uma equipe de cinco pesquisadores e compõem o banco de dados do estudo "Envel hecimento, saúde e trabalho: um estudo com idosos(as) que frequentam um espaço para convivência, orientação e pesquisa para idosos na cidade de São Paulo, coordenado por Brêtas ACP. Foi utilizada a técnica da entrevista, por meio do auxílio de um roteiro composto por questões semiestruturadas. As entrevistas duraram em média sessenta minutos e foram gravadas após a aquiescência dos depoentes, cabendo aos entrevistadores a transcrição textual.

Em 2005, o material transcrito foi devolvido aos narradores para avaliarem o seu teor, acrescentando ou retirando depoimentos. Apenas um dos idosos solicitou acréscimo de informações, o que foi assegurado prontamente pelos entrevistadores. Os demais narradores não fizeram nenhum tipo de sugestão.

Análise

Os dados selecionados pelos autores deste estudo foram analisados por meio da técnica da análise temática. Para operacionalizá-la, as narrativas foram trabal hadas à luz dos eixos temáticos história do envelhecimento ehistória do trabalho. Destes emergiram três categorias analíticas: o significado do envelhecimento/velhice, 0 significado do trabalho, o significado do enveInecimento no mercado de trabalho.

$\mathrm{O}$ projeto de pesquisa foi aprovado pelo $\mathrm{Co}$ mitêdeÉtica em Pesquisa da UniversidadeFederal deSão Paulo. Os procedimentos éticos inerentesa pesquisas dessa natureza, bem como a vigilância rigorosa das condições de utilização da técnica da entrevista e a sua adequação ao estudo, estiveram presentes em todas as etapas do trabalho.

\section{A presentação e análise dos dados}

Para facilitar a contextualização dos relatos obtidos, julgamos ser necessário, antes da apresentação e da análise dos resultados, descrever alguns dados sobre os sujeitos da pesquisa. Esclarecemos, no entanto, que tal descrição não retratará a totalidade das características dos narradores, apenas fornecerá uma noção parcial do conjunto dos entrevistados.

Dos seis idosos entrevistados, dois estão na faixa etária entre 60 e 69 anos; três na de 70 a 79; e um tem 80 anos ou mais. Quanto ao estado civil, duas são solteiras; dois casados e dois divorciados. No que diz respeito à renda, três recebem aposentadoria; dois o benefício de prestação continuada (BCP) euma sobrevive por meio da ajuda de amigos. Em relação à moradia atual, dois residem em casa própria; um na casa de filhos; dois em albergues municipais e uma na casa de amigos.

Para operacionalizar a análise dos dados, partimos da premissa de que os entrevistados compartilham a experiência de já terem vivenciado 0 processo de envelhecimento no mercado de trabalho, estando em plenas condições para objetivarem o nosso objeto de estudo ${ }^{6}$. Tal constatação nos levou a realizar recortes temáticos nas narrativas com a finalidade de estabelecer uma relação crítica entre os dados empíricos obtidos nos depoimentos e as categorias analíticas selecionadas. 
Destacamos que essa etapa do trabal ho centra-se na análise das narrativas coletadas e não na história de vida dos depoentes. Para efeito de apresentação dos dados, mantivemos a distinção entre os sujeitos colocando (M ou F) e (" $x$ " a.) após a citação dos relatos para identificar respectivamente 0 sexo e a idade do respondente. Para assegurar o sigilo acordado com os narradores, não utilizaremos nenhum dado que possa identificá-los.

Aos depoentes foi conferida a posi ção denarrador, pois o que interessava é que deixassem fluir o pensamento e, com isso, contar suas experiências, auxiliando na construção do imaginário coletivo ${ }^{7}$ referente ao processo de envelhecimento no mercado de trabal ho.

Se para alguns os depoimentos orais estão sob suspeita quanto a sua veracidade e credi bilidade, dada a subjetividade que Ihes é conferida, evidenciamos que toda fonte histórica derivada da percepção humana é subjetiva, mas apenas a fonte oral permite-nos desafiar essa subjetividade: descolar as camadas da memória, cavar fundo em suas sombras, na expectativa de atingir a verdade oculta ${ }^{8}$.

Assim, por mais quese deva à memória coletiva, é o indivíduo que recorda, é ele que tem acesso aos objetos, reminiscências do passado"; entretanto, a memória coletiva não éa soma nem a média das memórias individuais. D essas considerações, depreende-se queéfundamental o respeito à memória individual, poiscada depoimento éútil na medida em que retrata uma experiência; e é essa singularidade e essa especificidade que permitem a constatação e a construção do imaginário coletivo ${ }^{10}$.

Categoria 1 -

O significado do envelhecimento/vel hice

Como já mencionamos, para nós, os conceitos de envelhecimento evel hice são distintos, sendo que o envelhecimento é o processo vital no qual a velhiceestáinserida. Entretanto, depreendemos nas narrativas dos entrevistados que, para eles, essas palavras têm significados semel hantes- que nos leva a agrupá-las para efetivar a análise.

Observamos nos depoimentos que cada narrador percebe que está envelhecen do de uma for$\mathrm{ma}$, retratando seus valores e crenças com relação a esse processo, demarcando atitudes - quase sempre individuais diante do fato.

Para um, a percepção está associada às perdas funcionais, corroborando o que diz Elias quando discute a experiência do envelhecimento: não éfácil imaginar quenosso próprio corpo, tão cheio de frescor emuitas vezes de sensações agradáveis, pode ficar vagaroso, cansado e desajeitado. Não podemosimaginá-lo e, no fundo, não o queremos ${ }^{11}$ ( $p .80$ ).

A gentenão sente que está envelhecendo, mas a gente nota. Eu sinto uma canseira. Quando subo uma escada do metrô sinto uma fadiga, coisa queeu não tinha. Eu não corro, se corro sinto sair tudo pela boca - eu não era assim. Eu sinto que já estou ficando para as moscas, já não sou o mesmo. A gente sente que o corpo da gente envel hece ( $M, 65 \mathrm{a}$.).

Outra narrativa separa o racional do espiritual - destacando que as perdas funcionais devem ser compensadas por ganhos não materiais: No meu íntimo eu não estou envelhecendo. Eu não sou velha. 0 meu espírito não aceita. A minha matéria pode estar envelhecendo, mas o meu espírito não pode envelhecer. Ele tem que ser sempre jovem. Eletem que estar sempre atuante. Vocêtem que estar sempre se renovando. Isso é natural em mim, o meu espírito já faz porque aceitou a velhice, não aquela coisa da revolta. Você só fica velho quando a sua cabeça está velha. Sua matéria vai envelhecer, éclaro, há um desgastenatural. É como uma máquina. Você compra um automóvel 1950, cinquenta anos depois vai estar velho: só serve para você!!! Certo? (F, 67 a.).

Tal narrativa suscita a reflexão de que 0 ato deenvel hecer implica mudanças constantes, sendo que saber lidar com as perdas, buscando novas aquisições durante todo o processo de enveIhecimento, é o que o torna saudável. Um enveIhecimento será cada vez mais satisfatório quanto maior for o poder do indivíduo de assimilar e não renunciar às mudanças físicas, psicológicas e sociais, adaptando-se, sem sofrer em demasia, aos novos papéis sociais que desempenhará no decorrer da sua vida, ao passo que assim continuará a se sentir útil, desfazendo a ideia do "só serve para você".

Àsvezes, a percepção do próprio envelhecimento está vinculada à imagem corporal do outro, como destaca Beauvoir ao afirmar que a velhice aparece mais claramente para os outros do que para o próprio sujeito; ela é um novo estado de equilíbrio biológico: se a adaptação se opera sem choques, 0 indivíduo que envelhece não a percebe ${ }^{1}$ ( $p .348$ ).

Percebi que estava envelhecendo quando me dei conta do envelhecimento dos outros. (M , 79 a.). Por sua vez, o envelhecimento pode denotar sobrevida. Só fica vel ho quem consegue se manter vivo. Envelhecimento? Eu já estou velha. Já envelheci e eu não pensava em ficar velha. Eu não. Pensava queia morrer porque a minha mãe morreu não tinha 30 anos, meus irmãos morreram 
tudo prematuro, eu pensava que não ia [pausa]. Pra mim foi bom porquepassou depressa, não pensava em ficar velha. Eu não senti (F, 72 a.).

Envelhecer requer a destreza de saber viver cada uma das etapas do processo. Eu nunca pensei nisso (no envelhecimento). Vou explicar. A realidadeé nua e crua, se eu tenho hoje 73 anos eu não tenho mais 40 - ficou para trás. Eu não vou pensar - ah, quando eu tinha 40 ! Ah, quando eu tinha 35 ! Ah, meus 16 anos. Não, cada época éuma época. $\mathrm{H}$ oje eu estou com 73 anos, não penso no ano que eu tinha 16 anos, nem 40, nem 60. Eu tenho que pensar nessa época agora, de 73 ( $M, 73$ a.).

Vale destacar a não percepção do envelhecimento: Não percebi até hoje. Eu me sinto hoje da mesma forma quemesentia aos 50 anos ( $M, 80$ a.).

A noção da terminalidade humana vinculada ao processo de envel hecimento está presente em algumas narrativas, nas quais para os depoentes a finitude é tratada como algo inerente à vida. Envelhecer quer dizer morrer - hoje, amanhã - é inevitável. 0 mais inevitável na vida eu acho que é a morte, ninguém vai ficar sem passar por isso (M , 79 a.). Eu costumo definir que envelhecer é destacar a folhinha da parede. Só isso (M , 80 a.).

Depreendemos também no significado do envelhecimento/velhice a questão da associação da finitude humana ao comprometimento da capacidade funcional, por meio da qual temos 0 diálogo entre perdas físicas e conquistas sociais. Envelhecer ésentir quea vida está acabando para o ser humano, está acabando. Eu sinto muito canseira quando subo escada, eu sinto mesmo quenão sou mais aquele. Subida, eu ando devagarinho. M astem um lado bom, é a natureza - nós nascemos, fomos nenê, depois fomos rapaz, moça, e daí somos homensemulheres formados edaqui a pouco entra no envelhecimento - é uma coisa de Deus, uma coisa divina, eu acho bom, eu sinto quea pessoa que está envelhecendo tem mais respeito. Quando eu entro num ônibus e tem uma moça nova, um rapaz - "0 senhor senta aqui", eu sinto muito respeito nesta parte; metrô também - moça e rapaz bem vestido "o senhor senta aqui", a gentefica atésem jeito, com vergonha, aí eu não sento - "pode ficar sossegada, fazer a viagem de vocês sossegado" ( $M, 65$ a.).

Outra narrativa confere ao envelhecimento/ velhice o significado de perdas - salientando as que comprometem a capacidade funcional econtribuem para a estigmatização social do velho. Isso é triste. A pior coisa que existe no mundo éser velho, em todos os sentidos: moral, não, digo intelectual - porque te tira aquilo que tu tens - mais em respeito e dignidade, porque as pessoas não te respeitam mais. Velho não precisa de estatuto, pre- cisa ser respeitado. Envelhecer éuma porcaria. Você vai subir no ônibus, você não tem mais aquela força de impulsão. As suas pernas e os seus músculos já não são a mesma coisa, então dói. Você tem dores constantes. D ores mesmo. A musculatura vai envelhecendo, os ossos vão envelhecendo, a maté ria vai envelhecendo. Certo? ( $F, 67$ a.).

A pesar de o Estado, nas sociedades industrializadas, proteger o idoso - como qualquer outro cidadão - da violência física, o envelhecimento fragiliza o ser, contribuindo para o seu isolamento da sociedadee, portanto, do círculo da família e dos conhecidos ${ }^{11}$.

A relação corpo/máquina também está presente nos depoimentos, trazendo à reflexão a questão da terminalidade associada ao desgaste físico, por sua vez permeado pelos hábitos econdições de vida das pessoas durante o processo de envelhecimento. A velhice é a pior coisa feita ao ser humano pela natureza. E isso não tem dúvida que é a realidade. Porque na velhice você não tem mais a mesma atividade, começa a sentir desgaste inevitável, como eu disse das máquinas, principalmente quando ela não é bem mantida, não é bem ajustada, não tem uma manutenção perfeita, então se desgasta mais ligeiro emais profundamente. Aí vocêcomeça a perder habilidades, começa a perder agilidade, perder força atémental, vocêcomeça a esquecer coisas. É triste, éuma perspectiva. Q uando você começa a dar conta, aí pesa. A perspectiva de parar de tal maneira que você faz uma retrospectiva de quanta coisa quepoderia ser feita, quanto bem que eu poderia ter feito e adquirido e agora que, até daqui a pouco, você não tem mais tempo para fazer ( $M, 79$ a.).

As narrativas descrevem o envelhecimento com pessimismo, salientando que o ato de enveIhecer significa decadência física, mental e proximidade com a morte. Apenas uma delas reconheceque os velhos são dignos de respeito: Quando eu entro no ônibus tem uma moça, um rapaz "o senhor senta aqui..." - a gente fica até sem jeito... Entretanto, mesmo nesse contexto em quea velhice é reconhecida pelos mais jovens como merecedora de respeito, é sentida pelos idosos com constrangimento e vergonha.

A imagem que os idosos têm de si se aproxima das palavras de Beauvoir ${ }^{1}$, que afirma que 0 resultado de anos de exploração faz com que os seres humanos se tornem "refugos" e "destroços". Sentir-se "refugo" ou "a pior coisa que existe", ou ainda "a pior coisa feita ao ser humano", como afirmam alguns narradores, não é só uma imagem dos velhos sobresi, mas a de parte significativa da sociedade capitalista. 
Constatamos que quase sempre, no senso comum, a velhice é vista e sentida como um fardo, e o envelhecimento como o inverso da juventude.

0 escritor irlandês Oscar Wilde escreveu sobreo medo do envelhecimento eo desejo da eterna juventude em 0 retrato de Dorian Gray. Nesta obra, o jovem e belo Dorian, preocupado com o fim de sua mocidade, faz um pacto diante de seu retrato para se conservar eternamente jovem. Eu irei ficando velho feio, horrível. M as essequadro se conservará eternamente jovem. Nele nunca mais serei idoso. Se eu pudesse ser sempre moço, se 0 quadro envelhecesse!... Por isso, por esse milagreeu daria tudo! Daria até minha alma!12.

Embora as sociedades, de um modo geral, atribuam significados distintos às etapas da vida, com funções e importâncias diferenciadas - da infância até a vel hice--, éna sociedade capital ista que a velhice é percebida como a pior fase da vida. 0 idoso na sociedade capitalista é o velho, não 0 ancião. 0 velho nas sociedades précapitalistas era aquele que, pela sua longa experiência de vida e acúmulo de conhecimento, trazia marcado na memória e também no corpo a vivência de seu povo. A velhice era percebida como um sinal de sabedoria, consequentemente como núcleos de decisão, como os conselhos de anciãos da Roma Antiga.

Dorian Gray, como um homem moderno, assim como todas as narrativas aqui apresentadas, identifica a velhice principalmente como a perda da vitalidade física e mental, em nenhum momento como acúmulo de conhecimento ou experiência: é como uma máquina, você compra um automóvel 1950, cinquenta anos depoisvai estar velho, só serve pra você.

A descrição feita por Caetano Veloso em 0 homem velho mostra a velhice ou o velho como aquele que é a referência ou o "espelho" do mundo, não pela sua boa forma física ou mesmo pela sua aparência jovial, mas pela sua experiência de vida: 0 homem velho deixa vida e morte para trás I Cabeça a prumo, seguerumo enunca, nunca mais. / 0 grandeespel ho queéo mundo ousaria refletir os seus sinais / 0 homem velho é o rei dos animais / [...] / Osfilhos, filmes, ditos, livros como um vendaval / Espalham-no além da ilusão do seu ser pessoal / M as ele dói e brilha único, indivíduo, maravilha sem igual / Já tem coragem de saber queéimortal ${ }^{13}$.

Categoria 2 - 0 significado do trabalho

Todos os narradores, cada qual a sua maneira, ressaltam que o trabalho é importante para o ser humano. Observamos em algumas narrati- vas que eles compreendem o trabal ho como uma das essências da vida - tanto na perspectiva econômica como na psicossocial. Significa a coisa mais essencial na vida do indivíduo. Sem trabaIho, sem recurso, não há meio de vida. Então, o trabalho éimportante. Quando éfeito com prazer, com gosto, muito mais. Além do poder aquisitivo, do poder socioeconômico, tem também a disposição pessoal, o prazer de executar o trabalho. Se sentir satisfeito e dizer: eu sou uma pessoa, eu faço isso, está sob a minha responsabilidade, eu estou pronto para responder pelo que eu faço. 0 prazer também ( $M, 79$ a.).

Depreendemos também que, atrelado à fonte de ganho econômico, o trabal ho pode expressar atividade e dignidade. 0 trabalho para mim é condições de vida, de viver, exercício, toda pessoa tem que trabalhar. Para mim éisso, exercício para a pessoa não ficar muito parada. É um exercício e também um dom. Para mi méuma dignidadepara a pessoa, pra mim o trabalho éuma dignidade. No trabalho a gente esquece de muita coisa da vida da gente. Quando a gente está fazendo um serviço é uma higiene mental, porque a gente tá pensando só no serviço. Para mim éisso ( $F, 72$ a.).

Associado a esse pensamento, identificamos o sentido de utilidade conferido ao trabalho. 0 trabalho éo componente que ajuda muito no dia a dia porque sem trabalho o homem deixa de ser útil. Então eu acho que o trabalho é um componente muito sério na vida de um homem. Ele trabalhando éútil. Ele se sente bem e ajuda a resolver muitas coisas não só dele como também do próximo ( $M, 73$ a.). 0 trabalho faz com que a pessoa olhe menos para ela e para as suas mazelas. Então fica reclamando menos. Se senteútil, porqueo idoso gosta de se sentir útil. Tem uns que realmente gostam de ser úteis, gostam de trabalhar; tem outros que são preguiçosos mesmo, são vagal. Aquela pessoa que sempre teve uma atividade e que não fez do trabalho uma escravidão, ela sente prazer em trabalhar. Agora, todo aqueleque diz assim: "eu vou meaposentar e vou vestir o pijama", esse não trabalhou por prazer, esse trabalhou por obrigação. Então, ele vai vestir o pijama e o que vai acontecer? Em cinco ou seis anos ele está doente - aí ele vai perceber o quanto elefoi útil ou deixou de ser útil. Quer dizer - elefoi útil e não percebeu $(F, 67$ a.).

A contradição do trabalho - como fonte de sofrimento e prazer - também foi registrada. Olha, sinceramente, o trabalho para mim não é uma coisa necessária, não. É o que vocêfaz no seu trabalho queé necessário. Porque as pessoas falam assim - "eu preciso trabalhar senão eu enlouqueço". Não, então não é uma coisa prazerosa para 
você. Porque você tem que trabalhar com prazer. As pessoas trabal ham, trabalham porque é preciso viver. Preciso pagar minhas contas, preciso comer, preciso não sei o quê, preciso sei lá o quê. Eu preciso gastar, então eu preciso ganhar. Não. Isso não é trabalho. Isso é escravidão. 0 trabalho precisa ser uma coisa prazerosa. Vocêtem que estar constantemente trabalhando, mas com prazer. 0 trabalho para mim era diversão $(F, 67$ a.).

Em todos os depoimentos o trabal ho tem um significado positivo, quevai desdeo condicionamento físico e mental atéa atividadequedignifica aquele que a executa como um ser útil e responsável perante os outros. 0 trabalho faz 0 trabalhador esquecer suas próprias mazelas. Então fica reclamando menos.

Enquanto para a maioria das pessoas a noção de trabal ho é associada a uma atividade desgastante da qual procuramos escapar a todo custo na espera do feriado, das férias ou do fim de semana, os idosos narradores atribuem ao trabalho, independentemente dequal atividadeseja executada, a realização da própria vida

Max Weber, em A ética protestante e o espírito do capitalismo, destaca que a moderna forma de atividade econômica, na qual o trabalho passa a ocupar um lugar central na vida dos indivíduos, como uma vocação ou como um dom, deixa de ser uma crença religiosa e passa a dominar a moralidade mundana. A ética do trabalho é dar sentido à vida em um mundo desencantado ${ }^{14}$.

O capitalismo moderno ésem dúvida o sistema mais eficiente em termos de produtividade criado pelo ser humano. M as a própria racionalização que o tornou possível entra em choque com os valores da civilização ocidental, como a criatividadeindividual ea independência da ação.

0 trabalho é tido como obrigação moral do indivíduo; a sociedade cobra que todos produzam por meio dele. Aquele que não trabalha não está de acordo com a ética dessa sociedade. Isso repercute até mesmo naqueles que já trabalharam, adquiriram o direito à aposentadoria e, quando se aposentaram, continuam vítimas dessa ética. Os indivíduos, mesmo depois de terem passado a maior parte de suas vidas desempe nhando uma atividade especializada, monótona, sentem-se, quando longe dessa atividade, incompletos e/ou inúteis por estarem fora do mercado de trabalho.

A renúncia e o apelo ao trabalho são outra marca da sociedade moderna. Todo trabalho válido no mundo moderno significa a negação à universalidade faustiana ou, na expressão de M arx, alienação. E quea desvalorização do mun- do humano aumenta na mesma proporção que a valorização do mundo das coisas ${ }^{15}$.

Categoria 3 - O significado do

envelhecimento no mercado de trabalho

Para alguns narradores, o envel hecimento e o trabal ho são categorias distintas, corroborando o pensamento empírico hegemônico no qual éincomum o ser humano perceber que envel hece diuturnamente, portanto que envelhece no trabalho - independentemente desofrer ou não desgaste psicofísico.

Nessa linha de pensamento, a aposentadoria não éobservada como direito conquistado esim como o momento da mudança de papel social quase sempre estigmatizado. Os idosos, no Brasil, vivem com frequência angustiados com a desvalorização das aposentadorias e pensões ${ }^{16}$ - pela questão econômica em si, mas sobretudo em decorrência da perda de valor social. A ausência do trabalho muitas vezes é o que dá concretude ao envelhecimento/velhice. A pior coisa queeu fiz foi parar de trabalhar, foi não trabalhar. Tem um dito que diz que o ócio é a oficina do diabo. Portanto, não perca oportunidades, não pare de trabalhar (M, 79 a.).

Por sua vez, a ausência do exercício do direito à aposentadoria - dado o não cumprimento dos deveres em relação à Previdência Social - pode levar o idoso à situação de pobreza absoluta. Quando essa questão está associada ao alcoolismo e/ou desestruturação familiar, potencializase a possibilidade da vida em situação de rua, na qual o indivíduo passa a ser duplamente excluído - por ser velho e por ser pobre. Eu tenho saudade do trabalho, sempre trabalhei, mas o meu mal foi que eu nunca trabalhei registrado. Então, por causa do registro e da idade que eu tenho não dá para me aposentar - isso foi o meu mal e também muitos anos bebendo. Eu comecei a beber tinha 14 anos e parei agora - estou com 65 anos. M inha vida foi só bebida. Larguei a minha família por causa de bebida (, 65 a.).

Atrelado à aposentadoria, temos o risco do isolamento. Antes da morte física, o idoso vive a morte social ${ }^{11}$. A aposentadoria para mim foi muito triste porque se depender de mim eu estaria trabalhando atéhoje. Foi dolorido e eu, durante muito tempo eu [pausa] passei uma certa mágoa, uma certa tristeza atépor não estar trabalhando, não só porque a renda me ajudaria a ter um padrão de vida melhor, mas pelo trabalho em si - o relacionamento com as pessoas. Eu sinto falta desse relacionamento, desse contato com as pessoas ( $M, 80 \mathrm{a}$.). 
Quando o envelhecimento é observado em conjunção com o trabalho, observamos a inclusão das categorias doença e/ou idade para argumentar os motivos que fazem o indivíduo parar de trabalhar. Envelhecer éindependente do trabaIho. Envelhecer - todo mundo fica velho, é só viver. Enquanto está vivendo está ficando vel ho. Tem pessoa que não pode trabalhar porque é doente e outra quenão pode porquea idadenão dá. As pessoas são diferentes - tem pessoa que não trabalha porque não dá pra trabalhar mesmo - é a idade; outras por causa da doença - ével hice com doença, éruim. 0 trabalho faz falta. Eu tenho necessidade detrabalhar. Parecequeatrofia tudo se a gentenão trabalhar. Atrofia tudo (F, 72 a.).

Além de o trabalho proporcionar o salário meio para satisfazer as necessidades humanas , ele funciona como elemento central na manutenção da autoestima. 0 ambiente de trabalho possibilita a oportunidade de contatos com outras pessoas, bem como com atividades diferentes das domésticas. É nesseambienteque os indivíduos podem desempenhar funções que, mesmo sendo rotineiras, têm reconhecimento social.

A ausência de trabalho para a população economicamente ativa quasesempresignifica desemprego, e éum dos grandes problemas não só dos países em desenvolvimento como também dos de capitalismo avançado. No entanto, mesmo em cenários de desemprego estrutural, há possibilidade de empregabilidade formal ou informal para os mais jovens.

Quanto aosidosos, a ausência do emprego não é caracterizada como desemprego, pois esse grupo não faz parte da população economicamente ativa. Entretanto, significa que majoritariamenteeles serão pelo resto de suas vidas inativos na perspectiva socioeconômica. Esse quadro se agrava em sociedades que, embora capitalistas, não obtiveram os ganhos sociais, resultado de muitas lutas, de trabalhadores de capitalismo adiantado.

A inexistência ou ineficiência de um Estado de Bem-Estar Social, dado ao avanço de reformas neoliberais, faz com que a situação dos idosos, mesmo que aposentados, se torne cada vez pior. Assim, compreender a relação entre 0 envelhecimento e o trabalho nos remete ao pensamento de quea experiência deenvelhecer só épercebida quando assumimos que o processo de envelhecimento produz uma mudança fundamental na posição de uma pessoa na sociedade, e, portanto, em todas as suas relações com os outros. 0 poder e 0 status das pessoasmudam, rápida ou lentamente, mais cedo ou mais tarde, quando elas chegam aos sessenta, aos se tenta, oitenta ou noventa anos ${ }^{11}$ (p. 83).

\section{Consideraçõesfinais}

Este estudo reforça a tese de que as sociedades capitalistas supervalorizam o trabalho na vida dos seres humanos e, quando este deixa de ser vivenciado - pela aposentadoria ou pelo desemprego -, compromete a qualidade do envelhecimento/velhicedo indivíduo, principalmenteselhe faltarem habilidades e condições (individuais, sociais e econômicas) para incorporar e priorizar outras atividades e valores em sua vida.

Compreendemos que, no sistema capitalista, o trabalhador é obrigado a vender a sua força de trabalho para garantir a própria subsistência e/ou a de seus familiares. Entretanto, a forma quea força de trabal ho assume na sociedade capitalista como mercadoria - contribui para a percepção do idoso sobre o envelhecimento basicamente como perda das funções físicas e mentais, restando pouco saldo positivo para o processo deenvelhecimento ancorado no acúmulo de experiência e sabedoria.

Depreendemostambém queo envelhecimento ésilencioso, não é percebido na sua plenitude; na maior parte das vezes apenas é identificado quando o indivíduo tem comprometida a sua capacidade funcional, quando compara a sua imagem atual com fotos de tempos passados e/ ou com o envelhecimento de outras pessoas suas contemporâneas.

Quanto ao significado do envel hecimento no mercado de trabalho, as narrativas evidenciaram quea ausência do trabal ho pode ser substancialmente responsável pela redução da qualidade de vidaedeenvelhecimento/velhice. Destacamosque este fator pode ser projetado nas gerações futuras, caso não se tomem providências - individuais e coletivas - no sentido de (re) inventar diferentes estratégias de resistência para sobrevivência à expropriação do trabalho.

Salientamos, ainda, que a ausência do trabaIho em decorrência de políticas econômicas que levam ao desemprego estrutural pode ser substancialmente responsável pela minimização da qualidade de vida dos trabal hadores que, ao envelhecer, têm o agravante de encontrar chances reduzidas ao concorrer no mercado de trabal ho com pessoas mais jovens. Quando se aposentam, sua situação tende a piorar, pois os valores pagos aos aposentados não são suficientes para cobrir suas despesas; a isso se acresce a precariedade dos serviços públicos.

Outro ponto destacado foi o status social do idoso em uma sociedade que privilegia o novo ou a novidade. 0 afastamento dos idosos de suas famílias para as casas-lar, ou instituições de lon- 
ga permanência para idosos, significa um afastamento da vida pública - outro problema a ser enfrentado.

Acreditamos que assegurar o processo de envelhecimento com dignidade será o grandede- safio para os movimentos sociais atuais e futuros. Quanto à garantia da qualidade de vida, visualizamos que deverá ser reconquistada por meio de luta política e social que privilegie a dimensão ética do ser humano.

\section{Colaboradores}

RF Souza realizou a coleta, a transcrição ea análise dos dados e a redação do artigo. HA M atias participou da análise dos dados e da redação. ACP Brêtas planejou o estudo, participou da coleta, da transcrição e da análise dos dados e da redação final do artigo, tendo orientado a pesquisa.

\section{Referências}

1. Beauvoir S. A velhice. Rio de Janeiro: Nova Fronteira; 1990.

2. Brêtas ACP. Envelhecimento e trabalho. In: Oliveira EM, Scavone L, organizadoras. Trabalho, saúde e gênero na era da globalização. Goiânia: AB Editora; 1997. p. 61-67.

3. Marx K. O capital: crítica da economia política. 16a ed. Rio de Janeiro: Civilização Brasileira; 1998. (Livro 1. p. 221).

4. Engels F. 0 papel do trabalho na transformação do macaco em homem. 4a ed. São Paulo: Global Editora; 1990.

5. Lacaz FAC. O campo da saúde do trabalhador: resgatando conhecimentos e práticas sobre as relações trabalho e saúde. Cad. Saude Publica 2007; 23(4):757-766.

6. Bourdieu P. 0 poder simbólico. $2 \underline{a}$ ed. Rio de Janeiro: Bertrand Brasil; 1998.

7. Benjamin W. O narrador. In: Benjamin W, Horkheimer M, Adorno TW, Habermas J. Textos Escolhidos/Walter Benjamin, Max Horkheimer, Theodor W. Adorno, Jürgen Habermas. Tradução José Lino Grünnewald. 2a ed. São Paulo: Abril Cultural; 1983. p. 57-74. (Os Pensadores)

8. Thompson P. A voz do passado. Rio de Janeiro: Paz e Terra; 1992. p. 197.

9. Bosi E. M emória e sociedade: lembranças dos velhos. 2ª ed. São Paulo: EdUSP; 1987. p. 333.

10. Ariès P. 0 tempo da história. Rio de Janeiro: Francisco Alves; 1989.

11. Elias N. A solidão dos moribundos, seguido de EnveIhecer e morrer. Rio de Janeiro: Jorge Zahar Editor; 2001.

12. Wilde O. 0 retrato de Dorian Gray. São Paulo: Abril Cultural; 1972. p. 38.

13. Veloso C. O homem velho. [site na Internet] [acessado 2007 jan 5]. Disponível em: http://caetanoveloso.letras.terra.com.br

14. Weber M. A ética protestante e o espírito do capitalismo. São Paulo: Pioneira; 1967.

15. M arx K. M anuscritos econômico-filosóficos: terceiro manuscrito. Rio de Janeiro: Paz e Terra; 1974.

16. Veras R. Fórum Envelhecimento Populacional e as Informações de Saúde do PNAD: demandas e desafios contemporâneos. Introdução. Cad Saude Publica 2007; 23(10):2463-2466.

Artigo apresentado em 08/02/2007

Aprovado em 10/09/2007

Versão final apresentada em 05/03/2008 